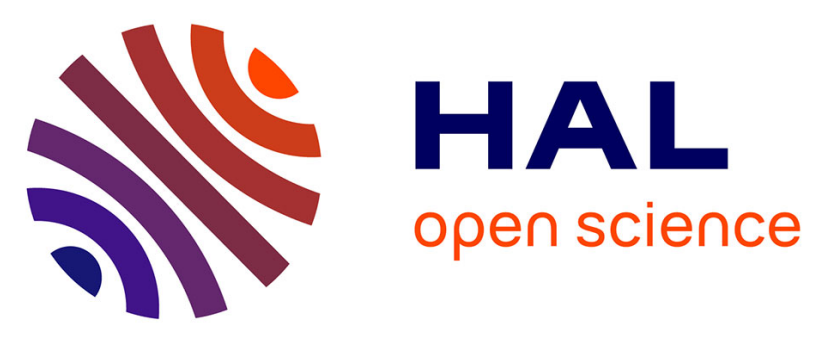

\title{
Synovial tissue rank ligand expression and radiographic progression in rheumatoid arthritis: observations from a proof-of-concept randomized clinical trial of cytokine blockade
}

Terence Rooney, Carl K. Edwards, Martina Gogarty, Laura Greenan, Douglas J. Veale, Oliver Fitzgerald, Jean-Michel Dayer, Barry Bresnihan

\section{To cite this version:}

Terence Rooney, Carl K. Edwards, Martina Gogarty, Laura Greenan, Douglas J. Veale, et al.. Synovial tissue rank ligand expression and radiographic progression in rheumatoid arthritis: observations from a proof-of-concept randomized clinical trial of cytokine blockade. Rheumatology International, 2009, 30 (12), pp.1571-1580. 10.1007/s00296-009-1191-1 . hal-00568309

\section{HAL Id: hal-00568309 https://hal.science/hal-00568309}

Submitted on 23 Feb 2011

HAL is a multi-disciplinary open access archive for the deposit and dissemination of scientific research documents, whether they are published or not. The documents may come from teaching and research institutions in France or abroad, or from public or private research centers.
L'archive ouverte pluridisciplinaire HAL, est destinée au dépôt et à la diffusion de documents scientifiques de niveau recherche, publiés ou non, émanant des établissements d'enseignement et de recherche français ou étrangers, des laboratoires publics ou privés. 
SYNOVIAL TISSUE RANK LIGAND EXPRESSION AND RADIOGRAPHIC PROGRESSION IN RHEUMATOID ARTHRITIS.

\section{OBSER VATIONS FROM A PROOF-OF-CONCEPT RANDOMIZED}

\section{CLINICAL TRIAL OF CYTOKINE BLOCKADE}

Terence Rooney ${ }^{1}$, Carl K Edwards, III $^{3}$, Martina Gogarty ${ }^{1}$, Laura Greenan ${ }^{1}$, Douglas J Veale $^{1}$, Oliver FitzGerald ${ }^{1}$, Jean-Michel Dayer ${ }^{2}$, Barry Bresnihan ${ }^{1}$

${ }^{1}$ Department of Rheumatology, St. Vincent's University Hospital, Dublin, Ireland, ${ }^{2}$ Division of Immunology and Allergy, University Hospital, Geneva, Switzerland

${ }^{3}$ Department of Inflammation Drug Discovery Research, Amgen, Inc., Thousand Oaks, CA 91360, USA

Supported by research grants from Amgen, inc.

\section{Corresponding author:}

Terence Rooney

Dept. of Rheumatology

St. Vincent's University Hospital

Dublin 4

Ireland

Tel.: (+353) 12774737

Fax: (+353) 12693541

e-mail: rooneyterence@gmail.com 


\section{ABSTRACT}

\section{Objective:}

To evaluate synovial tissue receptor activator of nuclear factor- $\kappa \beta$ ligand (RANKL) and osteoprotegerin (OPG) as biomarkers of disease activity, progressive joint damage, and therapeutic response, during cytokine blockade in rheumatoid arthritis (RA).

\section{Methods:}

Patients with active RA entered a randomized open-label 12-month study of anakinra $100 \mathrm{mg} /$ day, administered as monotherapy or in combination with pegsunercept $800 \mu \mathrm{g} / \mathrm{kg}$ twice weekly. Arthroscopic synovial tissue biopsies were obtained at baseline, at 4 weeks and at the final time-point. Following immunohistochemical staining, RANKL and OPG expression was quantified using digital image analysis (DIA). Radiographic damage was evaluated using the van der Heijde modification of the Sharp scoring system.

\section{Results:}

Twenty-two patients were randomized. Baseline expression of RANKL, but not OPG, correlated significantly with baseline CRP levels $(r=0.61, p<0.01)$. While a significant reduction in OPG expression following treatment was observed in clinical responders at the final timepoint ( $\mathrm{p}<0.05$ vs baseline), RANKL levels did not change, and the RANKL:OPG ratio remained unaltered, even at the highest levels of clinical response. When potential predictors of radiographic outcome were evaluated, baseline RANKL expression correlated with erosive progression at 1 year $(r=0.71, p<0.01)$.

\section{Conclusions:}

Distinct, though related, pathophysiologic processes mediate joint inflammation and destruction in RA. Elevated synovial tissue RANKL expression is associated with 
progressive joint erosion, and may be independent of the clinical response to targeted therapy. The potential therapeutic importance of modulating RANKL in RA is highlighted, if radiographic arrest is to be achieved. 


\section{INTRODUCTION}

Rheumatoid arthritis (RA) is a disabling, inflammatory arthropathy, commonly associated with progressive articular cartilage loss, bone erosion and deformity [1]. In recent years, the use of biologic therapies targeting specific mediators of inflammation and matrix destruction has been associated with enhanced control of joint inflammation and retardation of progressive structural joint damage [2-7].

A critical common pathway leading to localized articular bone erosion in RA involves the activation of RANK by RANKL, promoting differentiation of osteoclast progenitors into mature osteoclasts which effect bone resorption [8]. RANKL is detectable in T-cells and fibroblasts in RA synovial tissue, and its expression is regulated by many proinflammatory cytokines and their inhibitors [9]. OPG is a naturally occurring inhibitor of RANK / RANKL interaction, is also expressed in RA synovial tissue and acts as a potent regulator of osteoclastogenesis [9]. Therapies modulating the OPG / RANKL axis have resulted in retardation of joint destruction in animal models of inflammatory arthritis, and recently in patients with RA [10-14]. Although a number of previous studies have examined synovial tissue OPG / RANKL expression in RA, few have examined the expression of OPG and RANKL in RA synovial tissue before and after biologic therapy [15-22]. The aim of the present study was to evaluate the utility of synovial tissue levels of receptor RANKL and OPG as biomarkers of progressive structural joint damage, disease activity and therapeutic response, during a trial of selective cytokine blockade in RA. It was conducted as a component of the SPECTRA trial, a single centre, phase II open-label synovial tissue biopsy study, involving therapy with anakinra administered either alone or in combination with PEGylated soluble tumour necrosis factor (TNF) receptor type I (pegsunercept), for a planned duration of 52 weeks [23, 24]. 


\section{PATIENTS AND METHODS}

\section{Patients}

As previously described, eligible patients for the SPECTRA study were aged 18 years or older, had active RA of $\leq 10$ years duration diagnosed according to the 1987 revised American College of Rheumatology (ACR) criteria, and had $\geq 9$ tender joints (of 68 evaluated), $\geq 6$ swollen joints (of 66 evaluated), a clinically inflamed knee joint, and at least 2 of the following 3 criteria: morning stiffness lasting $\geq 45$ minutes, C-reactive protein $(\mathrm{CRP}) \geq 1.5 \mathrm{mg} / \mathrm{dl}$, erythrocyte sedimentation rate $(\mathrm{ESR}) \geq$ $28 \mathrm{~mm} / \mathrm{h}[23,25]$.

Major exclusion criteria included prior use of any $\mathrm{TNF} \alpha$ antagonist or anakinra, a history of any other major chronic inflammatory disease, malignancy (besides nonmelanoma skin carcinoma within 5 years) or demyelinating disorder, a positive tuberculin skin test, history of tuberculosis (TB) infection, or chest radiograph suggestive of prior $\mathrm{TB}$, any infection requiring systemic antibiotics within 12 weeks of screening, any uncontrolled medical condition, pregnancy or breast feeding, and ACR functional class IV disease [26].

Doses of concomitant RA therapies such as non-steroidal anti-inflammatory drugs (NSAIDs) and oral corticosteroids $(\leq 10 \mathrm{mg}$ /day of prednisolone or equivalent) must have been stable for 4 weeks prior to screening.

\section{Protocol}

Patients were recruited for this 52-week, single-center, open-label study at St. Vincent's University Hospital (SVUH), Dublin. A total of 30 patients were to be recruited. The protocol was approved by the institution's ethics committee, and patients gave their written informed consent. Patients were randomly assigned to 
receive self-administered single subcutaneous injections of either anakinra 100 $\mathrm{mg} /$ day, or anakinra $100 \mathrm{mg} /$ day plus pegsunercept $800 \mu \mathrm{g} / \mathrm{kg}$ twice weekly. Traditional DMARDs were discontinued at least 6 weeks prior to screening. Doses of concomitant NSAID therapy were kept constant throughout the study. If necessary, oral corticosteroid therapy could be temporarily increased for $\leq 2$ weeks up to twice during the study. Up to 2 intra-articular corticosteroid injections were also permitted if required.

\section{Clinical assessment}

ACR20, ACR50, and ACR70 responses were assessed at week 4, and at the final timepoint [27]. Patients who withdrew from the study prematurely due to active RA or adverse events were classified as non-responders. DAS28 scores were also calculated at baseline, week 4, and at the final timepoint [28].

\section{Radiographic assessment}

Radiographs of the hands and feet were obtained at baseline, and at weeks 24 and 52. Radiographic damage was quantified by 2 blinded observers (TR, BB) using the van der Heijde modification of the Sharp scoring system [29]. Modified Sharp scores were then calculated as the mean of the scores obtained by the 2 observers. The minimum clinically important difference (MCID) in radiographic scores over time was calculated as the smallest detectable difference (SDD) for these 2 observers using the limits of agreement method of Bland and Altman [30]. Progression scores below this threshold were classified as non-significant. Using an assumption of linear progression, inferred rates of annual radiographic progression prior to study entry were calculated using damage scores and disease duration at study baseline. 


\section{Acquisition and preparation of synovial tissue}

Each patient underwent arthroscopy of a clinically inflamed knee joint at baseline, immediately prior to commencing therapy. Arthroscopy of the same knee was repeated following 4 and 52 weeks of therapy, or at the time of withdrawal from the study. Multiple synovial tissue biopsies (at least 6) were obtained throughout the knee joint under local anaesthesia using a $2.7 \mathrm{~mm}$ arthroscope and $2.8 \mathrm{~mm}$ universal biopsy forceps (Karl Storz GmbH \& Co., Tuttlingen, Germany). The synovial tissue was prepared as previously described [31]. In brief, tissue samples were snap-frozen together en bloc in Tissue-Tek OCT (Miles Inc. Diagnostic Division, Elkhart, IN) by immersion in liquid nitrogen. Frozen blocks were stored in liquid nitrogen until sectioned for staining. Seven $\mu \mathrm{m}$ thick sections were cut in a cryostat and mounted on glass slides. The slides were fixed in acetone at room temperature for 10 minutes and stored at $-70^{\circ} \mathrm{C}$ until immunohistochemical analysis was performed. After thawing for 20 minutes at room temperature, sections were stained with anti-OPG (MAB 805, R\&D Systems, Minneapolis, USA) and anti-RANKL (sc-9073, Santa Cruz Biotechnology, Santa Cruz, USA). A standard three-stage immunoperoxidase method was used for each antibody (Vector Laboratories, Lumigen Inc., Southfiela, USA), and was followed by counterstaining with haematoxylin. Sections in which the relevant primary antibody was replaced with isotype-matched irrelevant primary antibodies served as negative controls.

\section{Microscopic analysis of synovial tissue.}

For each stained tissue section, a single 40X digital image was acquired as previously described [32]. All slides were coded to maintain operator blinding. Image acquisition, modification and analysis were performed using AnalySIS software (Soft Imaging Systems, Denver, Colorado) and a personal computer with Intel Pentium III 
$800 \mathrm{MHz}$ processor and Windows ${ }^{\mathrm{TM}} 2000$ Professional Version 5.0.2195 environment. For each antibody, separate threshold RGB values were specified for total tissue (blue or brown) and for positive stain (brown). These threshold values remained constant throughout the analysis of sections stained for a given marker. The mean optical density (MOD) was calculated for the positively stained areas of each image and expressed as a $\%$ of the maximum possible density. The integrated optical density (IOD) was then calculated as the product of the $\%$ tissue occupied by positive stain and the MOD.

\section{Study closure}

In February 2003, while recruitment was ongoing, preliminary analyses of the results of 2 larger phase 3 clinical trials evaluating therapy with anakinra plus either etanercept or pegsunercept in RA indicated an increased incidence of serious infection in patients receiving combination therapy [33]. All studies of combination anakinra plus anti-TNF $\alpha$ therapy were suspended. All patients involved in the present study were contacted and informed in person of the reasons behind the study's early closure. Final assessments (including arthroscopic synovial tissue biopsy) were obtained, and patients receiving combination therapy were offered monotherapy by their supervising physician. Following study closure, week 26 and 52 radiographs were obtained, where possible, from all remaining patients who had participated in the study.(Terrance- you did a nice job of writing this---sometime let's discuss the behind the scenes discussions over this. There were actually 2 -fold higher infections with the IL1ra+Enbrel versus the IL1ra+PEGsunercept therapy. Amgen did not want these data out there for obvious reasons.) 


\section{Statistical analysis}

Cross-sectional differences between pairs of patient groups were evaluated using the Mann-Whitney U test. Proportional differences between groups were evaluated using Chi-squared tests. The Wilcoxon signed ranks test was employed to examine longitudinal differences in variables between baseline and subsequent timepoints. Correlations were calculated using Spearman's Rho. For efficacy measures, intent-totreat analysis was performed for all patients who received at least one dose of study drug. The performance of baseline variables as predictors of radiographic progression (presence or absence of clinically significant progression) was evaluated using receiver operating characteristics (ROC) curves. A ROC curve plots sensitivity against 1-specificity for a range of values of a given independent variable, where that variable is being evaluated as a test for a dependent dichotomous variable, whose 2 possible values are typically taken as either "positive" or "negative". Area under the ROC curve (AUROC) values for a given predictor near 1 or 0 identify it as a good test for a specified outcome, while values near 0.5 indicate a poor test.

To evaluate the relationship between radiographic outcome and sustained expression of synovial OPG / RANKL during the course of the study, AUCs were calculated using baseline, week 4 and final timepoint tissue data. Linear change in these tissue biomarker levels between timepoints was assumed. Since the final timepoint differed between patients, time-averaged AUCs were calculated by dividing the AUC for each patient by the number of weeks from baseline to final biopsy, allowing inter-patient comparison. All statistical calculations were performed using SPSS software (version 11.0). Two-tailed significance testing was employed throughout, and p-values less than 0.05 were taken as significant. 


\section{RESULTS}

\section{Patient characteristics and outcomes}

Twenty-two patients were randomized to the monotherapy or combination therapy groups and consented to serial arthroscopic synovial biopsies. Baseline demographic and clinical characteristics have been described previously [23]. In brief, the median age was 52 years and 18 patients $(82 \%)$ were female. The median (range) disease duration was 23 (3-87) months, and 10 patients (46\%) had symptoms of RA for less than 1 year. Sixteen patients $(73 \%)$ were rheumatoid factor positive. The patient population had moderate to severe RA, and median tender and swollen joint counts were 20 (of 68) and 16 (of 66), respectively. Of the total patient group, 11 (50\%) were DMARD naïve; the median number of previous DMARDs was 1 . At the time of study closure, 3 patients (1 monotherapy, 2 combination) had completed 52 weeks of treatment, while 12 patients (6 in each treatment group) were receiving active treatment. These patients were withdrawn from the study at a median (range) timepoint of $31(12-47)$ weeks. All patients contributed a $2^{\text {nd }}$ synovial biopsy at 4 weeks and 16 contributed a $3^{\text {rd }}$ biopsy after a median (range) of $32(12-52)$ weeks. A total of 17 patients contributed post-baseline radiographic scores.

The clinical and radiographic outcomes are presented in association with the levels of OPG and RANKL expression on an individual patient basis in Table 1. Of the total study group, 11 patients (50\%) achieved an ACR20 response or better at the final timepoint. ACR20, 50 and 70 response rates at the final timepoint were 64\%, 64\% and $46 \%$ with combination therapy, and 36\%, 9\%, and $0 \%$ with monotherapy, respectively. Of the 15 patients with 12-month radiographic data, the proportions of responders (ACR20 or better) and non-responders who demonstrated clinically 
significant increases in total Sharp score were $28 \%$ and $40 \%$, respectively (there were no statistically significant differences between response groups).

\section{Baseline expression of OPG and RANKL in synovial tissue and progressive joint damage}

OPG and RANKL expression was observed in all synovial tissue sections evaluated. OPG expression was largely confined to endothelial cells, whereas RANKL was widely expressed by inflammatory cells within the lining layer, sublining layer and in perivascular regions. Levels of expression of both biomarkers varied widely in the total patient group (Table 1) - baseline IODs ranged from 4.2 to 20.9 for OPG and from 3.6 to 35.2 for RANKL expression. At baseline, there was a statistically significant correlation between synovial tissue RANKL expression and serum CRP levels (Spearman's Rho 0.61, $\mathrm{p}<0.01$ ), but not DAS28. There were no correlations between synovial tissue OPG expression and measures of disease activity.

In order to evaluate the potential utility of synovial tissue OPG and RANKL expression as predictors of progressive joint damage, correlations between baseline tissue biomarker levels, as well as the RANKL:OPG ratio, and changes in modified total Sharp, erosion and narrowing scores at 6 and 12 months were evaluated. ROC curve analysis was also employed to determine the ability of these baseline tissue signals to predict the occurrence of clinically meaningful progressive structural damage. For comparison, known predictors of radiographic outcome (ESR and serum CRP) were subjected to the same analysis. The results are presented in Table 2. Baseline RANKL expression correlated significantly with erosive progression at both the 6 and 12 month time-points and also demonstrated predictive utility in ROC curve analysis. Similar results were observed for the baseline RANKL:OPG ratio and 
erosive progression at 1 year. As expected, both ESR and CRP also demonstrated predictive utility for erosive progression at 6 and 12 months. No significant relationship between OPG expression at baseline and radiographic change was observed. Linear regression could not be performed as sufficient variables could not be normalized using transformation. When logistic regression was used to examine the predictive value of multiple baseline variables simultaneously, no variable emerged as independently predictive of significant progression in any measure of joint damage. Neither early changes in, nor sustained expression (time-averaged AUC) of either biomarker demonstrated any significant correlations with radiographic outcome (data not shown).

\section{Cross-sectional analysis of OPG and RANKL expression and disease activity}

The relationship between measures of disease activity and synovial tissue OPG / RANKL expression are presented in Table 3. RANKL expression correlated significantly with ESR and CRP levels at baseline and with CRP and DAS28 scores at week 4. Strikingly however, at the final timepoint (median 32 weeks) this relationship was lost, and Spearman's Rho values for correlations between RANKL and disease activity were as low as 0.03. A similar trend was observed for the RANKL:OPG ratio. OPG expression did not correlate significantly with disease activity in cross-sectional analysis at any timepoint.

\section{Effects of biologic therapy on OPG and RANKL expression in synovial tissue}

Sixteen of the 22 study patients had baseline, 4 week and final biopsies. Table 4 highlights changes in tissue OPG and RANKL expression after treatment in the total group, by ACR response, and in the individual treatment groups. No significant changes in median OPG and RANKL IOD values were observed after treatment in the 
total group, or in either therapeutic subgroup. Ten of the 16 patients demonstrated an ACR20 response. Changes in tissue levels of OPG correlated significantly with $\triangle \mathrm{DAS} 28$ at both the early and late time-points (Table 3: Spearman's Rho 0.45 and 0.59, respectively, $\mathrm{p}<0.05)$. In ACR20 responders, a statistically significant decrease in OPG expression from baseline was observed, which exceeded the minimal, nonsignificant change observed in patients who did not respond to treatment $(-33.7 \%$ vs $5.0 \%$, respectively, $\mathrm{p}<0.05)$. RANKL expression did not change significantly from baseline following therapy in the total group or in any clinical response subgroup.

\section{DISCUSSION}

This paper is the first to describe the utility of OPG and RANKL expression, quantified using computerized digital image analysis, as synovial tissue biomarkers of radiographic progression, disease activity and therapeutic response, exclusively during targeted cytokine blockade. These 2 biomarkers were detected in all synovial tissue sections evaluated. The intensity with which they were expressed varied widely between individual patients and timepoints. Baseline RANKL expression correlated with erosive progression at 6 and 12 months with a high level of statistical significance. In cross-sectional analysis, RANKL expression correlated with measures of disease activity at baseline and week 4, but not at the final timepoint, while OPG levels did not reflect disease activity. In longitudinal analysis following treatment, tissue OPG expression decreased significantly in clinical responders and changed in proportion to the magnitude of the therapeutic response, whereas neither RANKL expression nor the ratio of RANKL:OPG in synovial tissue changed significantly in any response subgroup.

A number of previous cross-sectional studies have evaluated synovial tissue or fluid levels of RANKL and OPG in RA [15-22, 34-36]. While synovial fluid RANKL, but 
not OPG levels, correlated with the acute phase response in one study of patients with active RA, the present study provides the first observation of a significant crosssectional correlation between measures of disease activity and RANKL in synovial tissue [34]. Several cross-sectional studies have highlighted differences in tissue RANKL and OPG expression between active and inactive RA or between RA and other diseases $[15,17,18]$. In 1 study evaluating RANKL expression in RA, SpA, OA and healthy controls, the highest tissue RANKL levels were observed in RA patients with active disease [15]. In a second study, OPG was absent from synovial tissue sections obtained from patients with active RA, in whom, conversely, the highest levels of RANKL expression were observed [17]. A significant inverse relationship between fluid levels of RANKL and OPG has been reported in patients with RA and OA, and when these patients were treated as a signal disease group [36].

In the present study, OPG levels decreased following targeted therapy in proportion to the clinical response, while RANKL remained unchanged from baseline at the final timepoint, despite substantial reductions in disease activity. The effects of therapy on OPG / RANKL expression in RA synovial tissue have been evaluated in 3 previous studies $[19,20,22]$. In the first, tissue OPG and RANKL were quantified in 18 patients before and 8 weeks after commencement of infliximab or etanercept therapy [20]. In keeping with the current findings, RANKL levels did not change significantly following treatment. However, in contrast to the observations arising from the present study, tissue OPG expression increased significantly following successful $\mathrm{TNF} \alpha$ blockade. In a second study from the same center, synovial biopsies were obtained from the knees of patients before and 2 weeks after a single intra-articular corticosteroid injection [19]. In this setting, OPG levels remained static, while RANKL expression decreased significantly following the therapeutic intervention. In 
a final study, patients receiving conventional DMARD therapy were followed with serial synovial biopsies for 3 years [22]. Longitudinal changes in tissue RANKL, but not OPG expression, reflected clinical and erosive change.

There are a number of possible reasons behind the discrepant OPG / RANKL signals observed among these studies. It is likely that differing therapies, designs, timeframes, staining, and quantification systems all contribute. In a study utilizing synovial tissue obtained from patients with spondylarthropathy, tissue OPG and RANKL signals differed substantially between differing antibodies [37]. The present study involved anakinra therapy in all patients. No previous studies have evaluated the effects of anakinra on synovial tissue OPG. It has been shown that IL-1 $\beta$ can stimulate OPG production from RA fibroblast-like synoviocytes [38]. It is biologically plausible, therefore, that therapy specifically antagonising this cytokine should result in OPG down-regulation.

A further novel aspect of the present study was the observation that high pretreatment synovial tissue RANKL levels and the ratio of tissue RANKL:OPG predicted progressive joint erosion, despite clinically effective targeted therapy. Two previous studies, both following observational cohorts, examined the potential utility of tissue RANKL as an early predictor of structural outcome in RA [18, 21]. In one, RANKL and OPG proteins were detected using immunofluorescence, while quantitative reverse transcription polymerase chain reaction was employed to detect RANKL mRNA in the second. In these studies, radiographic follow-up took place at timepoints between 2 and 3 years following the initial assessment. Unlike the present 1-year study, baseline tissue RANKL failed to predict subsequent progressive joint damage in either. It is likely that differing quantification methods, varying therapy, 
and the longer follow-up period account for the lack of predictive signal in these studies.

In keeping with a previous study, high baseline ESR and CRP levels, which correlated with RANKL expression, were also associated with subsequent radiographic progression in univariate analysis [39]. Multiple linear regression analysis would be required to examine whether the relationship between RANKL and erosive progression was independent of its correlation with the acute phase response. This was not possible in the present study as the data could not be sufficiently normalized by transformation. A larger sample size would serve to clarify this issue. The association observed in this study between intense RANKL expression at baseline and progressive articular erosion is, however, entirely consistent with the biologic role of this mediator. Failure of RANKL to decrease following clinically efficacious therapy is a possible explanation for the discordance between radiographic progression and the clinical response to targeted therapy that has been observed previously [40]. Moreover, in studies using animal models of RA to evaluate novel therapies targeting the RANKL pathway, radiographic benefit without clinical improvement was observed, in keeping with the hypothesis that distinct, though related mechanisms may underlie synovitis and joint destruction [11-13, 41]. These observations have recently been replicated in humans with denosumab, a monoclonal antibody which targets RANKL [14].

A number of important limitations should prompt caution in interpreting the findings from this study: the patient numbers were small, the study was terminated prematurely, and an anti-TNF monotherapy arm was not included. The study was not specifically powered to detect particular outcomes or inter-group differences. It would be desirable to employ multivariate analysis to evaluate whether the relationship 
between RANKL and erosive progression was independent, or reflecting other interactions. The sample size in this study precluded such an approach. Single primary antibodies were used to stain for RANKL and OPG. Ideally the signals observed in the study should be validated using other antibodies. Nevertheless, this is the first study in which a direct relationship between intense baseline synovial tissue expression of RANKL, a pivotal mediator of osteoclastogenesis, and progressive bone erosion has been described in RA. Excellent clinical responses to cytokine-targeted therapy were not necessarily accompanied by RANKL suppression in tissue. The potential therapeutic importance of modulating RANKL in RA is therefore highlighted, if radiographic arrest is to be achieved [9].

\section{ACKNOWLEDGMENTS}

This study was supported by research grants from Amgen inc. The authors would like to thank Evelyn Murphy and Ann Madigan for laboratory advice and assistance and for data collection.

\section{CONFLICT OF INTEREST}

The authors declare that they have no conflict of interest. 


\section{REFERENCES}

[1] Verstappen SM, Bijlsma JW, Verkleij H, Buskens E, Blaauw AA, ter Borg EJ, et al. Overview of work disability in rheumatoid arthritis patients as observed in cross-sectional and longitudinal surveys. Arthritis Rheum 2004;51(3):488-97.

[2] Bresnihan B, Newmark R, Robbins S, Genant HK. Effects of anakinra monotherapy on joint damage in patients with rheumatoid arthritis. Extension of a 24 week randomized, placebo-controlled trial. J Rheumatol 2004;31(6):1103-11.

[3] Lipsky PE, van der Heijde DM, St Clair EW, Furst DE, Breedveld FC, Kalden JR, et al. Infliximab and methotrexate in the treatment of rheumatoid arthritis. AntiTumor Necrosis Factor Trial in Rheumatoid Arthritis with Concomitant Therapy Study Group. N Engl J Med 2000;343(22):1594-602.

[4] Bathon JM, Martin RW, Fleischmann RM, Tesser JR, Schiff MH, Keystone EC, et al. A comparison of etanercept and methotrexate in patients with early rheumatoid arthritis. N Engl J Med 2000;343(22):1586-93.

[5] Keystone EC, Kavanaugh AF, Sharp JT, Tannenbaum H, Hua Y, Teoh LS, et al. Radiographic, clinical, and functional outcomes of treatment with adalimumab (a human anti-tumor necrosis factor monoclonal antibody) in patients with active rheumatoid arthritis receiving concomitant methotrexate therapy: a randomized, placebo-controlled, 52-week trial. Arthritis Rheum 2004;50(5):1400-11.

[6] Cohen SB, Emery P, Greenwald MW, Dougados M, Furie RA, Genovese MC, et al. Rituximab for rheumatoid arthritis refractory to anti-tumor necrosis factor therapy: Results of a multicenter, randomized, double-blind, placebo-controlled, phase III trial evaluating primary efficacy and safety at twenty-four weeks. Arthritis Rheum 2006;54(9):2793-806. 
[7] Kremer JM, Genant HK, Moreland LW, Russell AS, Emery P, Abud-Mendoza C, et al. Effects of abatacept in patients with methotrexate-resistant active rheumatoid arthritis: a randomized trial. Ann Intern Med 2006;144(12):865-76.

[8] Goldring SR. Pathogenesis of bone and cartilage destruction in rheumatoid arthritis. Rheumatology (Oxford) 2003;42 Suppl 2:ii11-6.

[9] Schett G, Hayer S, Zwerina J, Redlich K, Smolen JS. Mechanisms of Disease: the link between RANKL and arthritic bone disease. Nature clinical practice 2005;1(1):47-54.

[10] Stolina M, Adamu S, Ominsky M, Dwyer D, Asuncion F, Geng Z, et al. RANKL is a marker and mediator of local and systemic bone loss in two rat models of inflammatory arthritis. J Bone Miner Res 2005;20(10):1756-65.

[11] Redlich K, Hayer S, Maier A, Dunstan CR, Tohidast-Akrad M, Lang S, et al. Tumor necrosis factor alpha-mediated joint destruction is inhibited by targeting osteoclasts with osteoprotegerin. Arthritis Rheum 2002;46(3):785-92.

[12] Zwerina J, Hayer S, Tohidast-Akrad M, Bergmeister H, Redlich K, Feige U, et al. Single and combined inhibition of tumor necrosis factor, interleukin-1, and RANKL pathways in tumor necrosis factor-induced arthritis: effects on synovial inflammation, bone erosion, and cartilage destruction. Arthritis Rheum 2004;50(1):277-90.

[13] Romas E, Sims NA, Hards DK, Lindsay M, Quinn JW, Ryan PF, et al. Osteoprotegerin reduces osteoclast numbers and prevents bone erosion in collageninduced arthritis. The American journal of pathology 2002;161(4):1419-27.

[14] Cohen SB, Dore RK, Lane NE, Ory PA, Peterfy CG, Sharp JT, et al. Denosumab treatment effects on structural damage, bone mineral density, and bone turnover in rheumatoid arthritis: a twelve-month, multicenter, randomized, double- 
blind, placebo-controlled, phase II clinical trial. Arthritis Rheum 2008;58(5):1299309.

[15] Crotti TN, Smith MD, Weedon H, Ahern MJ, Findlay DM, Kraan M, et al. Receptor activator NF-kappaB ligand (RANKL) expression in synovial tissue from patients with rheumatoid arthritis, spondyloarthropathy, osteoarthritis, and from normal patients: semiquantitative and quantitative analysis. Ann Rheum Dis 2002;61(12):1047-54.

[16] Crotti TN, Ahern MJ, Lange K, Weedon H, Coleman M, Roberts-Thomson PJ, et al. Variability of RANKL and osteoprotegerin staining in synovial tissue from patients with active rheumatoid arthritis: quantification using color video image analysis. J Rheumatol 2003;30(11):2319-24.

[17] Haynes DR, Barg E, Crotti TN, Holding C, Weedon H, Atkins GJ, et al. Osteoprotegerin expression in synovial tissue from patients with rheumatoid arthritis, spondyloarthropathies and osteoarthritis and normal controls. Rheumatology (Oxford) $2003 ; 42(1): 123-34$.

[18] Fonseca JE, Cortez-Dias N, Francisco A, Sobral M, Canhao H, Resende C, et al. Inflammatory cell infiltrate and RANKL/OPG expression in rheumatoid synovium: comparison with other inflammatory arthropathies and correlation with outcome. Clinical and experimental rheumatology 2005;23(2):185-92.

[19] Makrygiannakis D, af Klint E, Catrina SB, Botusan IR, Klareskog E, Klareskog L, et al. Intraarticular corticosteroids decrease synovial RANKL expression in inflammatory arthritis. Arthritis Rheum 2006;54(5):1463-72.

[20] Catrina AI, af Klint E, Ernestam S, Catrina SB, Makrygiannakis D, Botusan IR, et al. Anti-tumor necrosis factor therapy increases synovial osteoprotegerin expression in rheumatoid arthritis. Arthritis Rheum 2006;54(1):76-81. 
[21] Kirkham BW, Lassere MN, Edmonds JP, Juhasz KM, Bird PA, Lee CS, et al. Synovial membrane cytokine expression is predictive of joint damage progression in rheumatoid arthritis: a two-year prospective study (the DAMAGE study cohort). Arthritis Rheum 2006;54(4):1122-31.

[22] Haynes D, Crotti T, Weedon H, Slavotinek J, Au V, Coleman M, et al. Modulation of RANKL and osteoprotegerin expression in synovial tissue from patients with rheumatoid arthritis in response to disease-modifying antirheumatic drug treatment and correlation with radiologic outcome. Arthritis and rheumatism 2008;59(7):911-20.

[23] Rooney T, Roux-Lombard P, Veale DJ, FitzGerald O, Dayer JM, Bresnihan B. Synovial Tissue and Serum Biomarkers of Disease Activity, Therapeutic Response and Radiographic Progression. Analysis of a Proof-of-Concept Randomized Clinical Trial of Cytokine Blockade. . Annals of the Rheumatic Diseases, in press 2009.

[24] Edwards CK, 3rd, Martin SW, Seely J, Kinstler O, Buckel S, Bendele AM, et al. Design of PEGylated soluble tumor necrosis factor receptor type I (PEG sTNF-RI) for chronic inflammatory diseases. Adv Drug Deliv Rev 2003;55(10):1315-36.

[25] Arnett FC, Edworthy SM, Bloch DA, McShane DJ, Fries JF, Cooper NS, et al. The American Rheumatism Association 1987 revised criteria for the classification of rheumatoid arthritis. Arthritis Rheum 1988;31(3):315-24.

[26] Hochberg MC, Chang RW, Dwosh I, Lindsey S, Pincus T, Wolfe F. The American College of Rheumatology 1991 revised criteria for the classification of global functional status in rheumatoid arthritis. Arthritis Rheum 1992;35(5):498-502.

[27] Felson DT, Anderson JJ, Boers M, Bombardier C, Furst D, Goldsmith C, et al. American College of Rheumatology. Preliminary definition of improvement in rheumatoid arthritis. Arthritis Rheum 1995;38(6):727-35. 
[28] Prevoo ML, van 't Hof MA, Kuper HH, van Leeuwen MA, van de Putte LB, van Riel PL. Modified disease activity scores that include twenty-eight-joint counts. Development and validation in a prospective longitudinal study of patients with rheumatoid arthritis. Arthritis Rheum 1995;38(1):44-8.

[29] van der Heijde D. How to read radiographs according to the Sharp/van der Heijde method. J Rheumatol 2000;27(1):261-3.

[30] Bland JM, Altman DG. Statistical methods for assessing agreement between two methods of clinical measurement. Lancet 1986;1(8476):307-10.

[31] Rooney T, Murphy E, Benito M, Roux-Lombard P, FitzGerald O, Dayer JM, et al. Synovial tissue interleukin-18 expression and the response to treatment in patients with inflammatory arthritis. Ann Rheum Dis 2004;63(11):1393-8.

[32] Rooney T, Bresnihan B, Andersson U, Gogarty M, Kraan M, Schumacher HR, et al. Microscopic measurement of inflammation in synovial tissue: inter-observer agreement for manual quantitative, semiquantitative and computerised digital image analysis. Ann Rheum Dis 2007;66(12):1656-60.

[33] Genovese MC, Cohen S, Moreland L, Lium D, Robbins S, Newmark R, et al. Combination therapy with etanercept and anakinra in the treatment of patients with rheumatoid arthritis who have been treated unsuccessfully with methotrexate. Arthritis Rheum 2004;50(5):1412-9.

[34] Hein GE, Meister M, Oelzner P, Franke S. sRANKL and OPG in serum and synovial fluid of patients with rheumatoid arthritis in comparison to non-destructive chronic arthritis. Rheumatol Int 2008.

[35] Feuerherm AJ, Borset M, Seidel C, Sundan A, Leistad L, Ostensen M, et al. Elevated levels of osteoprotegerin (OPG) and hepatocyte growth factor (HGF) in rheumatoid arthritis. Scandinavian journal of rheumatology 2001;30(4):229-34. 
[36] Skoumal M, Kolarz G, Haberhauer G, Woloszczuk W, Hawa G, Klingler A. Osteoprotegerin and the receptor activator of NF-kappa B ligand in the serum and synovial fluid. A comparison of patients with longstanding rheumatoid arthritis and osteoarthritis. Rheumatol Int 2005;26(1):63-9.

[37] Vandooren B, Cantaert T, Noordenbos T, Tak PP, Baeten D. The abundant synovial expression of the RANK/RANKL/Osteoprotegerin system in peripheral spondylarthritis is partially disconnected from inflammation. Arthritis and rheumatism 2008;58(3):718-29.

[38] Yano K, Nakagawa N, Yasuda H, Tsuda E, Higashio K. Synovial cells from a patient with rheumatoid arthritis produce osteoclastogenesis inhibitory factor/osteoprotegerin: reciprocal regulation of the production by inflammatory cytokines and basic fibroblast growth factor. Journal of bone and mineral metabolism 2001;19(6):365-72.

[39] Scott DL. Prognostic factors in early rheumatoid arthritis. Rheumatology (Oxford) 2000;39 Suppl 1:24-9.

[40] Smolen JS, Han C, Bala M, Maini RN, Kalden JR, van der Heijde D, et al. Evidence of radiographic benefit of treatment with infliximab plus methotrexate in rheumatoid arthritis patients who had no clinical improvement: a detailed subanalysis of data from the anti-tumor necrosis factor trial in rheumatoid arthritis with concomitant therapy study. Arthritis Rheum 2005;52(4):1020-30.

[41] van den Berg WB, van Riel PL. Uncoupling of inflammation and destruction in rheumatoid arthritis: myth or reality? Arthritis Rheum 2005;52(4):995-9.

Table 1. Synovial tissue OPG/RANKL expression and radiographic scores in individual patients, arranged according to clinical response. 
Patient ACR response Treatment group

OPG, IOD

RANKL, IOD

\section{Baseline Week 4 Final $\quad$ Baseline Week 4 Final}

$\begin{array}{ccccccccc}1 & \text { ACR70 } & 2 & 15.1 & 7.0 & 5.2 & 23.6 & 8.6 & 6.8 \\ 2 & \text { ACR70 } & 2 & 6.2 & 3.5 & . & 11.1 & 5.4 & \cdot \\ 3 & \text { ACR70 } & 2 & 5.7 & 7.4 & 5.1 & 13.6 & 8.2 & 14.7 \\ 4 & \text { ACR70 } & 2 & 20.9 & 20.4 & 8.5 & 17.4 & 26.2 & 26.6 \\ 5 & \text { ACR70 } & 2 & 12.7 & 15.8 & 14.3 & 16.7 & 8.5 & 16.6 \\ 6 & \text { ACR50 } & 1 & 9.5 & 8.9 & 6.3 & 12.7 & 10.4 & 9.8 \\ 7 & \text { ACR50 } & 2 & 6.9 & 9.4 & 1.7 & 3.6 & 5.0 & 5.4 \\ 8 & \text { ACR50 } & 2 & 7.1 & 7.8 & 5.7 & 14.6 & 15.8 & 4.8 \\ 9 & \text { ACR20 } & 1 & 19.4 & 7.0 & 9.7 & 4.4 & 11.4 & 5.0\end{array}$

$\begin{array}{rcccccccc}10 & \text { ACR20 } & 1 & 6.6 & 4.1 & \cdot & 17.6 & 17.2 & 4.7 \\ 11 & \text { ACR20 } & 1 & 11.9 & 9.1 & 11.7 & 31.1 & 23.7 & 33.0 \\ 12 & - & 2 & 8.5 & 1.4 & \cdot & 18.6 & 5.5 & \cdot \\ 13 & - & 1 & 6.0 & 8.6 & . & 8.4 & 6.3 & \cdot \\ 14 & - & 1 & 10.0 & 9.1 & . & 13.9 & 11.5 & \cdot \\ 15 & - & 2 & 8.5 & 6.4 & 10.1 & 9.5 & 8.9 & 10.5 \\ 16 & - & 1 & 8.5 & 12.6 & 7.3 & 8.5 & 20.2 & 13.6 \\ 17 & - & 1 & 4.2 & 10.2 & 9.0 & 4.5 & 14.1 & 18.7 \\ 18 & - & 1 & 14.5 & 10.3 & 7.5 & 24.0 & 19.9 & 6.0 \\ 19 & - & 2 & 9.2 & 17.2 & 8.5 & 11.2 & 20.7 & 7.4 \\ 20 & - & 2 & 6.8 & 4.5 & 8.0 & 9.5 & 13.7 & 13.8 \\ 21 & - & 1 & 7.0 & 7.8 & . & 22.6 & 19.5 & \cdot \\ 22 & - & 1 & 18.0 & 22.0 & . & 35.2 & 19.0 & .\end{array}$


$\mathrm{OPG}=$ osteoprotegerin, $\mathrm{RANKL}=$ receptor activator of $\mathrm{NF}-\mathrm{kB} . \mathrm{ACR}$ responses are at final timepoint. Treatment group 1 received anakinra, group 2 received anakinra + pegsunercept.

IOD = integrated optical density. Patients with clinically significant radiographic progression are highlighted in grey. See text for further definitions.

Table 2. Baseline synovial tissue RANKL, OPG and progressive structural damage

$\Delta$ Joint space

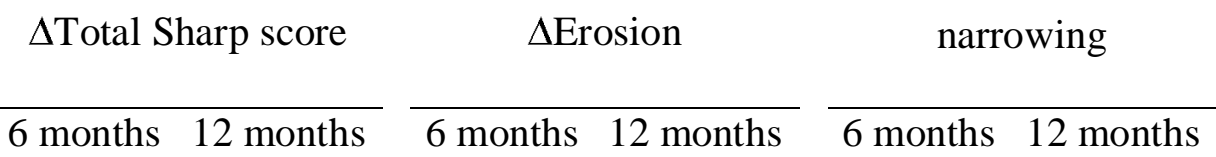

$\begin{array}{lcccccc}\text { OPG } & -0.02 & -0.09 & 0.18 & 0.14 & -0.11 & -0.10 \\ \text { RANKL } & 0.39 & 0.45 & 0.59 * & 0.73 * * \dagger & 0.12 & 0.11 \\ \text { RANKL:OPG ratio } & 0.38 & 0.57 * & 0.42 & 0.61 * \dagger & 0.19 & 0.30 \\ \text { ESR } & 0.52 * & 0.53 * \dagger & 0.45 & 0.60 * \dagger \dagger & 0.49 * & 0.44 \\ \text { CRP } & 0.51 * & 0.58 * \dagger & 0.50 * \dagger & 0.78 * * \dagger & 0.34 & 0.32\end{array}$

$\Delta$ denotes change. All values are Spearman's Rho. ${ }^{*} \mathrm{P}<0.05, * * \mathrm{P}<0.01$ for correlations.

$\dagger \mathrm{P}<0.05, \dagger \dagger \mathrm{P}<0.01$ for areas under ROC curves. ROC curves were constructed using baseline biomarkers as test variables and presence or lack of clinically significant progression in structural damage as outcome. See text and Table 1 for further definitions.

Table 3. Synovial tissue OPG/RANKL expression and disease activity 


\begin{tabular}{cccc} 
ESR & & \multicolumn{2}{c}{ CRP } \\
${$\cline { 1 - 1 }$}$ Change $\dagger }$ & & Cross-section & Change $\dagger$
\end{tabular}

OPG

$\begin{array}{llll}\text { Baseline } & 0.13 & - & 0.28\end{array}$

Week 4

0.07

0.04

0.24

0.20

Final

0.10

$0.60 *$

0.24

0.50

RANKL

Baseline

$0.44^{*}$

$-$

$0.61 * *$

Week 4

0.36

0.03

$0.59 * *$

0.10

Final

$-0.05$

0.46

0.03

0.33

RANKL:OPG ratio

Baseline

0.36

$0.47 *$

Week 4

0.18

$-0.16$

0.14

$-0.28$

Final

$-0.42$

$-0.10$

$-0.20$

0.03

Values are Spearman's Rho. $\uparrow$ Refers to correlation between change in synovial tissue marker and change in disease activity variable.

$* \mathrm{P}<0.05$, ** $\mathrm{P}<0.01$. See Table 1 for further definitions.

Table 4. Changes in synovial tissue OPG/RANKL by clinical response and treatment group

Total Group

$\mathrm{n}=22$

$(\mathrm{n}=16 \mathrm{w}$. final biopsy)

\section{ACR20}

$\mathrm{n}=11$

$(\mathrm{n}=10$ w. final biopsy $) \quad(\mathrm{n}=7$ 
OPG

Baseline IOD

Week $4 \%$ change

Final $\%$ change

RANKL

Baseline IOD

$13.7(9.2,19.6)$

$-15.4(-41.3,45.7)$

$7.0(-58.8,48.8)$

Final \% change

RANKL:OPG ratio

Baseline

Week $4 \%$ change

Final $\%$ change
$8.5(6.8,13.1)$

$-4.3(-35.7,31.3)$

$-13.6(-50.3,13.3)$
$1.4(1.1,2.1)$

$-0.4(-21.2,55.6)$

$16.1(-16.6,94.9)$
$9.5(6.6,15.1)$

$-6.4(-43.7,24.7)$

$-33.7(-62.4,-6.6)^{*}+$

$-33$

14

$-29$

$-0$
$14.6(11.1,17.6)$

$-18.3(-49.1,38.9)$

$2.8(-68.1,23.7)$

$-0.5(-20.6,54.3)$

$16.1(-14.4,203.9)$

IOD $=$ integrated optical density. $* \mathrm{P}<0.05, * * \mathrm{P}<0.01$ for change from baseline. $\ddagger$ $\mathrm{P}<0.05$ vs. non-responders. See Table 1 for further definitions. 